\title{
Induction of Somatic Embryogenesis and Organogenesis in Zimbabwean Sweet Potato (cv Brondal)
}

\author{
Rose T. Masekesa, ${ }^{1}$ Edmore Gasura ${ }^{D},{ }^{1}$ Gaudencia T. Kujeke, ${ }^{1}$ Elizabeth Ngadze, ${ }^{1}$ \\ and Farisai Chidzwondo ${ }^{2}$ \\ ${ }^{1}$ Department of Plant Production Sciences and Technologies, Faculty of Agriculture, Environment and Food Systems, \\ University of Zimbabwe, P. O. Box MP 167, Mount Pleasant, Harare, Zimbabwe \\ ${ }^{2}$ Department of Biochemistry, Faculty of Science, University of Zimbabwe, P. O. Box MP 167, Mount Pleasant, Harare, Zimbabwe
}

Correspondence should be addressed to Edmore Gasura; gasurae@yahoo.com

Received 19 March 2021; Accepted 15 May 2021; Published 22 May 2021

Academic Editor: Mudassar Iqbal

Copyright (c) 2021 Rose T. Masekesa et al. This is an open access article distributed under the Creative Commons Attribution License, which permits unrestricted use, distribution, and reproduction in any medium, provided the original work is properly cited.

\begin{abstract}
Somatic embryogenesis (SE) and organogenesis are crucial in the development of disease free plants and genetic engineering. An investigation was conducted on the ability of treatments containing a combination of 2,4-D and Kinetin to induce either SE or organogenesis from cultured sweet potato cv Brondal leaves. Ten treatments were evaluated and each treatment had an exclusive combination of 2,4-D (at $0.05,0.1,0.2,0.5$ or $1 \mathrm{mg} / \mathrm{L}$ ) to kinetin (at either 0.1 or $0.5 \mathrm{mg} / \mathrm{L}$ ). Callus initiation occurred earlier in treatments containing higher hormonal concentrations. The 2,4-D to Kinetin ratio had a highly significant $(p=0.001)$ effect on callus growth and proliferation. Increasing 2,4-D to Kinetin ratio promoted profuse explant callusing while increasing Kinetin to 2,4-D ratio suppressed callusing but encouraged organogenesis, in particular shoot production (treatment containing $0.05 \mathrm{mg} / \mathrm{L}$ 2,4-D and $0.5 \mathrm{mg} / \mathrm{L}$ Kinetin). Embryogenic calli were formed seven weeks after leaf culture in the treatment containing $0.5 \mathrm{mg} / \mathrm{L}$ 2,4-D and $0.1 \mathrm{mg} / \mathrm{L}$ Kinetin. The embryogenic calli that developed from this treatment emerged from previously nonembryogenic calli. Plantlets produced via the SE pathway proved to be weak and unviable and died within four weeks of germination. In contrast, plantlets produced under organogenesis were strong, grew vigorously, and could be subcultured several times. This disparity may be accounted for by the fact that the cv Brondal embryos that developed under SE were not exposed to an embryo maturation staged before plantlet germination was initiated. The maturation stage would have assisted embryos to reach physiological maturity and a desired level of desiccation, both being critical elements in embryo to plantlet conversion. In this experiment, cv Brondal regeneration from leaf explants was successfully achieved via organogenesis using $0.05 \mathrm{mg} / \mathrm{L} \mathrm{2,4-D}$ and $0.5 \mathrm{mg} / \mathrm{L}$ Kinetin, and tentative steps towards development of SE based regeneration protocol were established using $0.5 \mathrm{mg} / \mathrm{L} 2,4-$ $\mathrm{D}$ and $0.1 \mathrm{mg} / \mathrm{L}$ Kinetin.
\end{abstract}

\section{Introduction}

Sweet potato (Ipomoea batatas L.) is ranked as the seventh most important crop after wheat, rice, maize, potato, barley, and cassava [1]. The tuber bearing plant is vegetatively propagated and is mainly cultivated for its storage roots [2]. Globally 128 million tonnes of sweet potato are produced each year and these are used for human consumption and animal feed [3] or in industry for starch extraction or ethanol production [4]. The crop's tubers are highly nutritious and are rich sources of carbohydrates $(37 \%)$, protein $(1.6 \%)$, vitamin $\mathrm{A}$, vitamin $\mathrm{B}$ complex, vitamin $\mathrm{C}$, folic acid, and phosphorous $(0.3 \%)$ [5]. In addition to being nutrient fortified, sweet potato has proven to be an effective on-farm food security crop to farmers [6]. In fact, smallholder farmers in Zimbabwe depend on the sweet potato crop to feed their families and to generate income through sell of tubers and vines [6].

The importance of plant tissue culture techniques in sweet potato propagation cannot be underscored. Tissue culture has been used as a tool to preserve germplasm, in the rapid production of disease free plant propagules $[7,8]$ and 
regeneration protocols have been used to aid in the genetic improvement of sweet potato $[9,10]$. Since the early 1980 s sweet potato regeneration has been reported for several cultivars and has been proceeded via somatic embryogenesis (SE) or organogenesis pathways $[11,12]$. The SE pathway is generally accepted to be the better route for plant regeneration since by its very nature, it tends to lead to the production of a greater number of regenerates compared to the organogenesis pathway $[13,14]$. Furthermore, in genetic engineering experiments, it is important to avoid the development of chimeric plants and any possible escapes [15]. Regeneration via SE can help to achieve this ideal state as the regenerated plantlets would have originated from a single cell [12]. However, SE does have the disadvantage that due to the prolonged culture requirements necessary to achieve somatic embryogenesis, this can lead to somaclonal variation [16]. Here, organogenesis has an advantage over SE as the plantlets regenerated via organogenesis not only grow faster but also tend be true to type $[17,18]$.

Since regeneration is genotype dependent and sweet potato cultivars generally tend to be recalcitrant to regeneration, it becomes important therefore to develop regeneration protocols that specifically suit local sweet potato cultivars. Although Zimbabwe's highest yielding sweet potato $\mathrm{cV}$ Brondal has been regenerated using the organogenesis pathway [19], it would be of paramount importance to be able to regenerate this cultivar via SE as this would facilitate the improvement of the crop via genetic engineering. The objective of this study is to develop a somatic embryogenesis regeneration protocol for Zimbabwean sweet potato $c v$ Brondal using leaves as explants. Ten (10) hormonal treatments composed of 2,4-D and Kinetin combinations were evaluated on effect on time to callus initiation, callus growth/proliferation, callus type, and mode of plantlet regeneration.

\section{Materials and Methods}

2.1. Planting Material. Field growing sweet potato $c v$ Brondal vines were obtained from Agribiotech (Pvt, Ltd), Harare, Zimbabwe. All the leaves attached to the vines were removed and the leafless vines were cut into three nodal sections, 4-6 cm long. The nodal cuttings were then washed with soapy water to remove surface debris adhering to the explants. Next the cv Brondal segments were placed under running tap water for three hours in order to create an isotonic solution inside the plant segment. After the wash stage, the cv Brondal segments were surface sterilized in $20 \%$ sodium hypochlorite (jik) solution for 15 minutes. This procedure was performed in the Laminar Airflow Hood (L.A.H. model Slee London). The sterilized vine segments were then rinsed thrice with sterile distilled water to remove the disinfecting jik. After sterilizing the forceps and blade with a Bead sterilizer (Simon Keller AG, steri 350 at $250^{\circ} \mathrm{C}$ ), forceps were then used to move the sterilized stem sections into jam jars containing a basal media of cotton and $2 \%$ sucrose. After four weeks, the cultured vines had produced sufficient mother stock plants to be subcultured onto plain solid Murashige and Skoog (MS) [20] media with $2 \%$ sucrose. The subcultured plants were then allowed to grow for a further four weeks. During the second round of subculture, the leaf explants were isolated into Petri dishes that contained the 10 hormonal media treatments listed in Table 1.

2.2. Culture Media Preparation. Leaf explants were cultured onto solid media containing MS prescribed salt nutrients supplemented with $100 \mathrm{mg} / \mathrm{L}$ Myo-inositol, $2 \mathrm{mg} / \mathrm{L}$ Glycine, $1 \mathrm{mg} / \mathrm{L}$ Nicotinic acid, $1 \mathrm{mg} / \mathrm{L}$ Pyridoxine, $0.2 \mathrm{mg} / \mathrm{L}$ Thiamine, $30 \mathrm{~g}$ sucrose, and $10 \mathrm{~g} / \mathrm{L}$ agar. Two growth regulators 2,4-D and Kinetin were then added to the MS to make up the respective treatments as outlined in Table 1. Stock solutions for the two hormones were made by dissolving $50 \mathrm{mg}$ hormone in small amounts of $0.5 \mathrm{M} \mathrm{NaOH}$ for kinetin and small amounts of ethanol for 2,4-D. When the hormones had dissolved, the stock solution volume was brought up to $50 \mathrm{ml}$ to make $1 \mathrm{mg} / \mathrm{ml}$ stock solutions. Once hormones were added to the MS media, distilled water was then added to bring up the volume to a litre of media. Next, $\mathrm{pH}$ was adjusted to $\mathrm{pH} 5.6-5.8$ using $0.1 \mathrm{M} \mathrm{NaOH}$ and $1 \mathrm{M} \mathrm{HCl}$ solutions. The prepared media was then sterilized by autoclaving for 15 minutes at $121^{\circ} \mathrm{C}$ then poured into Petri dishes ( $25 \mathrm{ml}$ of media into each).

Whole leaves measuring between 5-6 $\mathrm{mm}$ were selected for culture on the hormonal media treatments. Once the leaf explants were placed onto the Petri dishes, they were then macerated slightly to aid diffusion of hormones into the leaves before being partially embedded into the media with the midrib facing downwards. Each Petri dish had ten leaves in it and there was one Petri dish per treatment per block in three blocks. This made a total of 300 experimental units. The experiment was laid out as a randomized complete block design (RCBD) with 10 treatments.

2.3. Statistical Analysis. Data obtained was subjected to analysis of variance as suggested by Snedecor and Cochran [21]. Means were separated by using $5 \%$ least significant difference (LSD). To improve the normality of the data, transformation was done as suggested by Snedecor and Cochran [21].

\section{Results}

3.1. Experimental Focus 1. The experimental focus 1 was on the effect of hormonal treatments on length of time required to observe explant response, callus initiation, compact calli, and embryogenic calli formation under culture conditions.

Within six days of culture, leaf explants in nine of the 10 treatments used exhibited a swollen appearance. This observation, however, was absent in treatment 6 whose explants remained unresponsive to treatment conditions but instead remained fresh green. On calli initiation, it took treatments $1,2,3,4$, and 5 less than 19 days to initiate callus formation from cultured leaves (Figure 1). In contrast, treatments $7,8,9$, and 10 took between an average of 21 days to initiate callus formation from leaf cultures (Figure 1). Seven weeks after leaf culture, the nature of calli formed 
TABLE 1: Treatment number and corresponding 2,4-D to Kinetin concentrations and ratios in MS Media used in callus initiation, callus growth/proliferation, and plant regeneration from cultured cv Brondal leaves.

\begin{tabular}{lccc}
\hline Treatment number & $2,4-\mathrm{D}(\mathrm{mg} / \mathrm{L})$ & Kinetin $(\mathrm{mg} / \mathrm{L})$ & $\begin{array}{c}\text { 2,4-D: Kinetin } \\
\text { Ratio }\end{array}$ \\
\hline 1 & 0.05 & 0.1 & $1: 2$ \\
2 & 0.1 & 0.1 & $1: 1$ \\
3 & 0.2 & 0.1 & $2: 1$ \\
4 & 0.5 & 0.1 & $5: 1$ \\
5 & 1.0 & 0.1 & $10: 1$ \\
6 & 0.05 & 0.5 & $1: 10$ \\
7 & 0.1 & 0.5 & $1: 5$ \\
8 & 0.2 & 0.5 & $1: 2.5$ \\
9 & 0.5 & 0.5 & $1: 1$ \\
10 & 1.0 & 0.5 & $2: 1$ \\
\hline
\end{tabular}

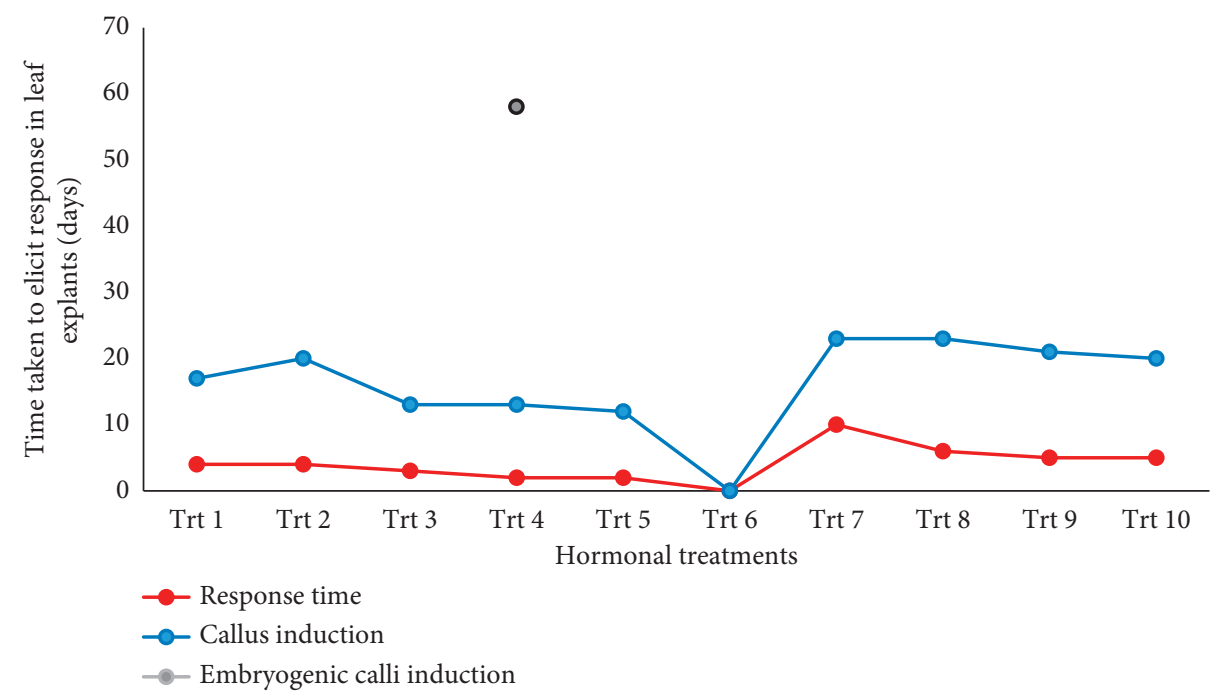

Figure 1: Time taken (in days) to initiate compact/embryogenic callus formation from cultured sweet potato cv Brondal leaves.

under treatment 4 began to shift from being nonembryogenic in nature to embryogenic. No such shift in calli characteristics was noted for the rest the treatments, even after 15 weeks of continued observation. During the entire period of culture, treatment 6 produced no callus phase at all.

\subsection{Experimental Focus 2}

3.2.1. Effect of Hormonal Treatments on Callus Growth and Proliferation. All treatments used in the study had the ability to promote callus formation from the cultured leaf explants except for treatment 6 . The treatments had a highly significant $(p=0.001)$ effect on callus diameter and calli height (Figure 2). For calli height, the treatments fell into five distinct groups, and each group is significantly $(p=0.001)$ different from the other. Treatments 7,8 , and 10 produced calli with the lowest heights of $0.37 \mathrm{~cm}, 0.40 \mathrm{~cm}$, and $0.39 \mathrm{~cm}$, respectively, and thus could be clustered together. Treatments 5 (calli height at $0.62 \mathrm{~cm}$ ) and 9 (calli height at $0.63 \mathrm{~cm}$ ) could also be congregated together as there were not significantly $(p>0.05)$ different from each other.
Treatments 2 and 3 were not significantly different from each other with treatment means of $1.21 \mathrm{~cm}$ and $1.22 \mathrm{~cm}$, respectively. Treatments 1 and 4 each fell into individual groups with treatment means of $1.13 \mathrm{~cm}$ and $1.59 \mathrm{~cm}$, respectively.

Analysis of calli diameter showed treatments having a highly significant $(p=0.001)$ different from each other. The treatments could also be placed into eight distinct groups with four of these groups overlapping. Where calli diameter was concerned, treatment 2 and 3 were not significantly different from each other, having treatment means of $1.76 \mathrm{~cm}$ and $1.85 \mathrm{~cm}$, respectively. Treatments 1,4 , and 10 each fell into individual groups having treatment means of $1.63 \mathrm{~cm}, 2.1 \mathrm{~cm}$, and $0.96 \mathrm{~cm}$, respectively. Treatment 8 (with calli diameter of $1.26 \mathrm{~cm}$ ) and treatment 7 (with calli diameter of $1.21 \mathrm{~cm}$ ) appear as individual groups which overlap each other. Likewise, treatment 5 (calli diameter of $1.37 \mathrm{~cm}$ ) and treatment 9 (calli diameter of $1.31 \mathrm{~cm}$ ) appear as individual groups that overlap with each other. Treatment 6 was excluded from the analysis as the treatment had no callus phase. The effect of different 2,4-D to Kinetin concentrations on number of plants regenerated from cultured cv Brondal also varied (Figure 3). 


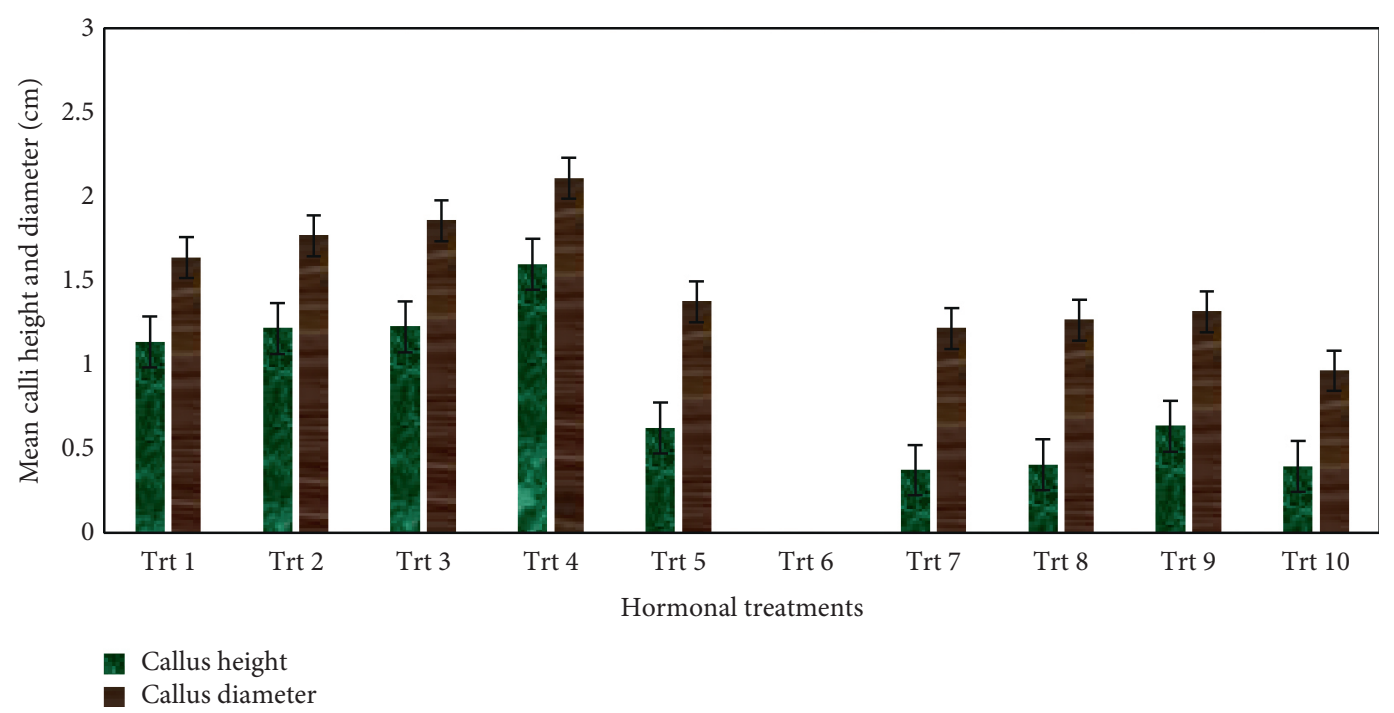

Figure 2: Effect of different 2,4-D to Kinetin concentrations and ratios on callus growth and proliferation (in $\mathrm{cm}$ ).

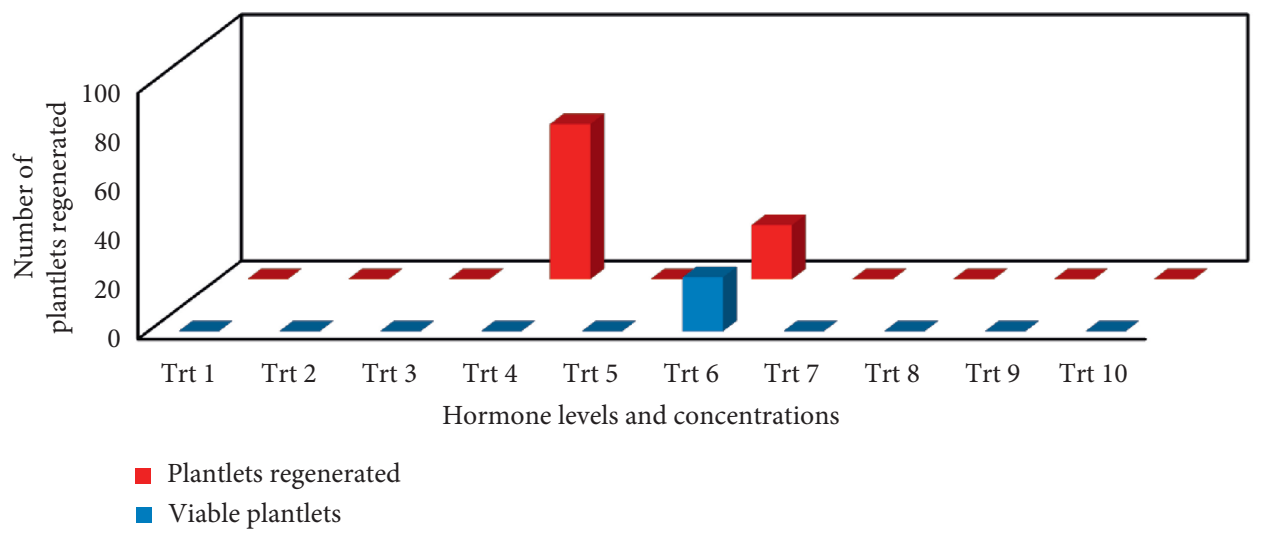

Figure 3: Effect of different 2,4-D to Kinetin concentrations and ratios on number of plants (viable and nonviable) regenerated from cultured sweet potato $\mathrm{cv}$ Brondal leaves.

\subsection{Experimental Focus 3}

3.3.1. Effect of Hormonal Treatments on Callus Morphology and Classification. Three distinctively different calli (in terms of type, nature, colour, morphology, and texture) developed from the cultured leaf explants under the 10 hormonal treatments used (Table 2). The calli that developed under treatments 1, 2, and 3 exhibited similar characteristics. These first three treatments produced calli that was compact, translucent green in colour, and nonembryogenic in nature (Table 2). Treatments 5, 7, 8, 9, and 10 also had calli that exhibited similar characteristics. The calli under these 5 treatments was deep green in colour, compact in texture, and nonembryogenic in nature. Treatment 4 produced an entirely unique type of calli which was nonembryogenic in nature in the first seven weeks of culture. However, after the seventh week, the top portion of this nonembryogenic calli began to exhibit embryogenic calli characteristics as depicted in Figure 4 . The calli under treatment 4 had an off-whitish colour and was compact in texture. In sharp contrast to the rest of the treatments, treatment 6 produced no calli phase at all during the entire 15 weeks of culture.

\subsection{Experimental Focus 4}

3.4.1. Effect of Hormonal Treatments on Total Number of Plantlets Regenerated and Number of Viable Regenerated Plantlets. Of the 10 treatments used to induce plantlet regeneration only two, treatment 4 and treatment 6 were capable of encouraging plantlet development from cultured $\mathrm{cV}$ Brondal leaf explants (Figure 3). The rest of the treatments 1, $2,3,5,7,8,9$, and treatment 10 failed to induce plant regeneration (Figure 3). Treatment 6 produced an average of 22 plantlets per 30 leaf explants cultured compared to treatment 4 which produced over 60 plantlets per 30 leaf explants cultured. All plantlets developed under treatment 6 proved to be viable, established successfully when isolated from the mother leaf explant and continued to function independently and be subcultured several times (Figure 4). This, however, 
TABLE 2: Effect of different 2,4-D to Kinetin ratios on callus colour, morphology, and subsequent classification of calli that developed from cultured sweet potato cr Brondal leaves.

\begin{tabular}{lccc}
\hline Media type & Calli colour & Calli morphology/texture & Calli classification \\
\hline Treatment 1 & Translucent green & Compact & Nonembryogenic \\
Treatment 2 & Translucent green & Compact & Nonembryogenic \\
Treatment 3 & Translucent green & Compact & Nonembryogenic \\
Treatment 4 & Off-white & Compact & Embryogenic \\
Treatment 5 & Green & Compact & Nonembryogenic \\
Treatment 6 & $*$ & $*$ & $*$ \\
Treatment 7 & Green & Compact & Nonembryogenic \\
Treatment 8 & Green & Compact & Nonembryogenic \\
Treatment 9 & Green & Compact & Nonembryogenic \\
Treatment 10 & Green & Compact & Nonembryogenic \\
\hline
\end{tabular}

${ }^{*}$ Media did not produce a callus phase from the cultured leaf explants.

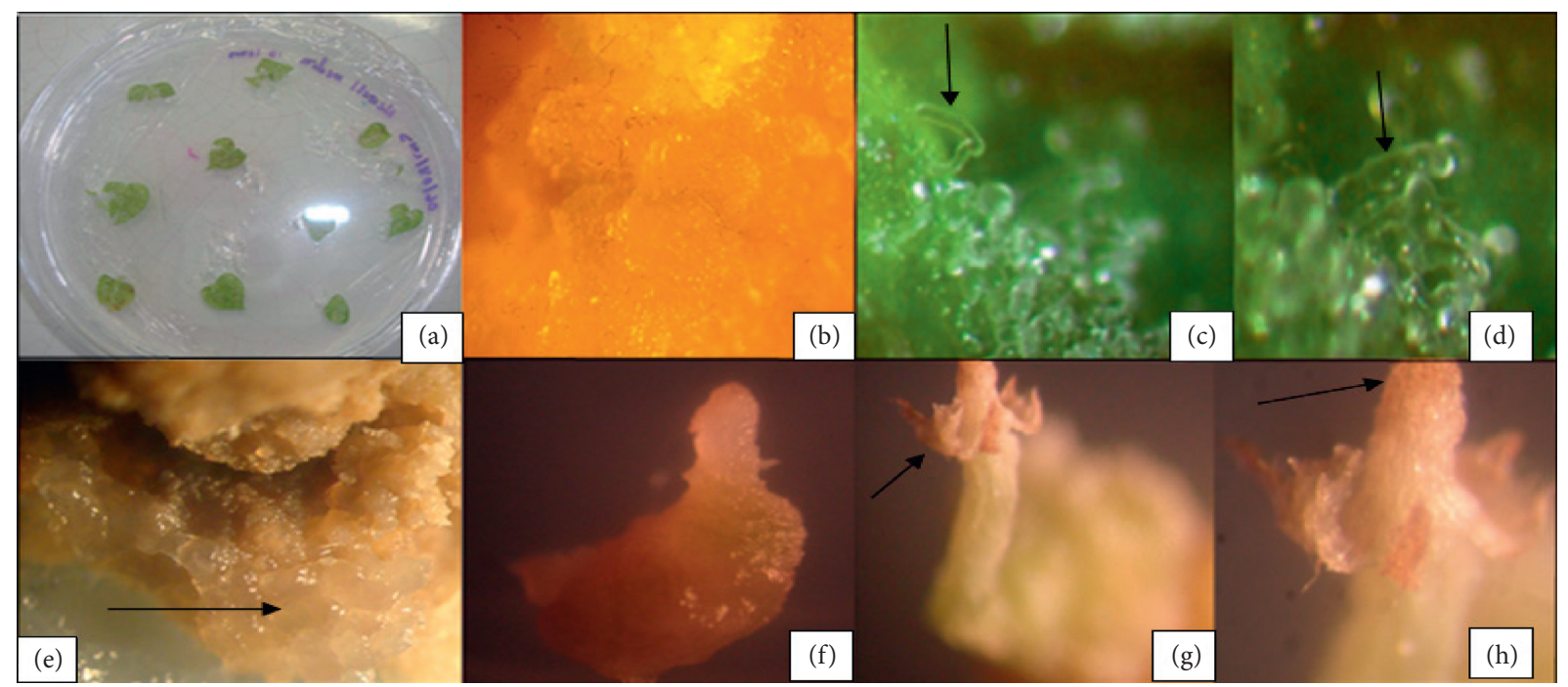

FIGURE 4: Somatic embryogenesis initiation and subsequent plantlet regeneration from cv Brondal leaves cultured on MS media supplemented with $0.5 \mathrm{mg} / \mathrm{L} 2,4-\mathrm{D}$ and $0.1 \mathrm{mg} / \mathrm{L}$ Kinetin which is Treatment 4; (A) 10 slightly macerated leaf explants/Petri dish. (B) Cluster of spherical immature somatic embryos. (C) The development of a suspensor from a basal embroyogenic cell. (D) A four-cell embryo at the quadrant stage of development (indicated by arrow). (E) Cluster of torpedo shaped embryos. (F) Shoot germinating from a mature embryo. (G) Plantlet development, arrow points to emerging leaves exhibiting a tinge of red, a typical characteristic of cv Brondal leaves. (H) Arrow pointing to apical meristem on regenerated cv Brondal shoot.

was not the case with the plantlets produced under treatment 4. Despite the high number of plantlets produced under treatment 4 , none of these proved to be viable as the plantlets failed to develop into fully functional plants, e.g., fully expanded leaves or any roots (Figure 5). Instead, plantlets regenerated on treatment 4 began to dry up three weeks after germination (beginning at the apical meristem) despite several media changes to try to sustain the plantlets.

\section{Discussion}

Genotype, tissue type, and developmental stage of donor plant are strong determining factors in how an explant responds to stimuli from auxin or cytokine [22]. In this study, the effect of varying the 2,4-D to Kinetin ratio was assessed in order to determine treatment ability to induce either somatic embryogenesis or organogenesis from $\mathrm{cv}$ Brondal leaf tissues. The effect of each treatment on callus initiation, callus proliferation, and nature of callus produced and ability to regenerate viable shoots from cultured $\mathrm{cv}$ Brondal leaves was also assessed.

Tissue response time to culture conditions and callus induction was much earlier in treatments containing higher concentrations of 2,4-D and Kinetin compared to those treatments with lower hormonal levels. Likewise, Sefasi et al.[14] and Sivparsad and Gubba [12], while working with sweet potato landraces observed a strong positive correlation between explant response, callusing, and increased hormone concentration. This observation may be due to the fact that 2,4-D [23] and Kinetin [24] are strong promoters of cell division and expansion and that higher levels of these hormones in media would elicit quicker response and callusing in cultured explants.

In the experiment, it was also observed that increasing the 2,4-D to Kinetin ratio promoted profuse explant callusing. This was in keeping with the findings of Vahedi 


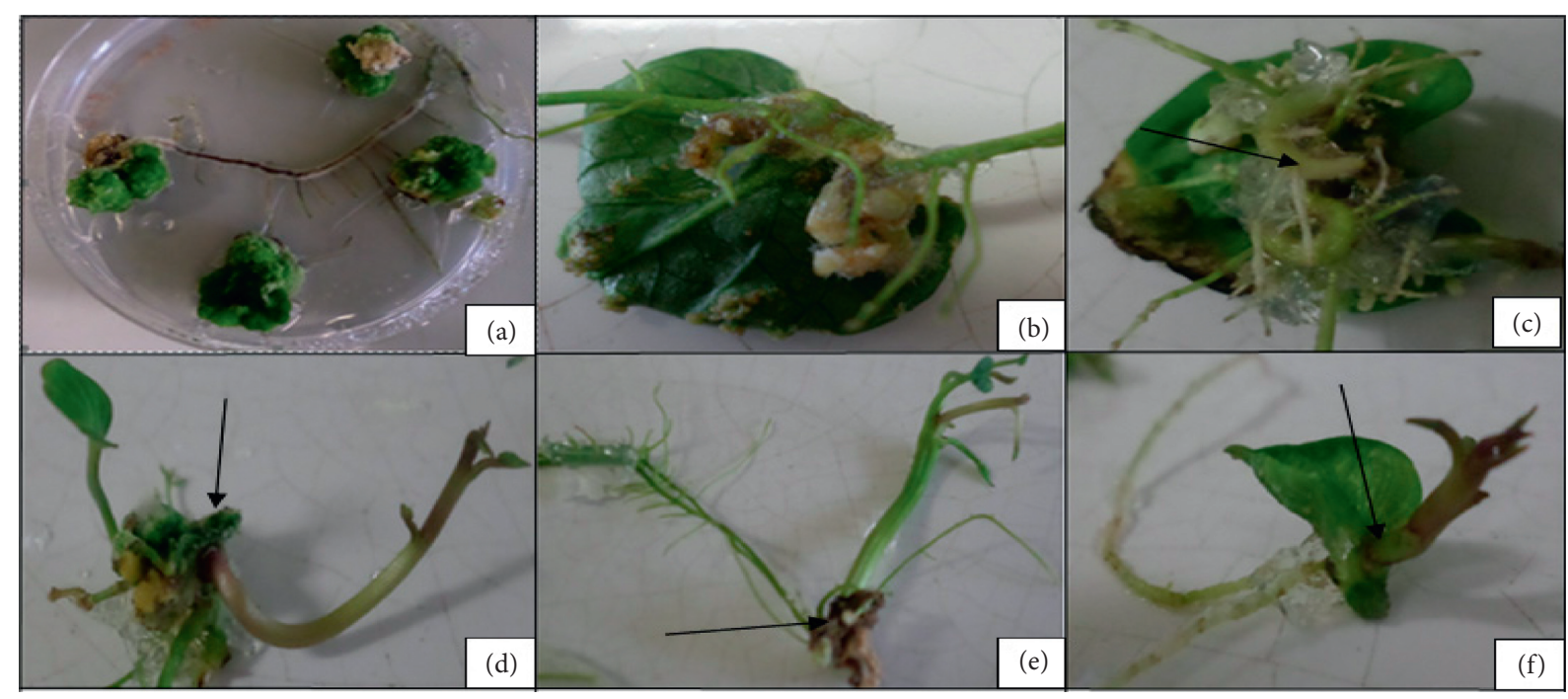

FIGURE 5: Direct and indirect organogenesis and subsequent plantlet regeneration from cv Brondal leaves cultured on MS media supplemented with $0.05 \mathrm{mg} / \mathrm{L} 2,4-\mathrm{D}$ and $0.5 \mathrm{mg} / \mathrm{L}$ Kinetin which is Treatment 6; (A) Callus and root development from cultured Brondal leaf explants. (B) and (C) Extensive rhizogenesis without an intermediate callus phase on MS media supplemented with $0.05 \mathrm{mg} / \mathrm{L} \mathrm{2,4-D}$ and $0.5 \mathrm{mg} / \mathrm{L}$ Kinetin. (D) Two separate plantlets regenerating from a single leaf explant (indicated by arrow). (E) Shoot development. Arrow points to the leaf explant (now dried up) from which a shoot originated. (F) A plantlet and roots emerging directly from a cultured leaf explant.

et al.[25] and Rashid et al.[26] who were working on Saffron and wheat, respectively. Decreasing the 2,4-D to Kinetin ratio, however, leads to the suppression of callus formation promoting direct organogenesis. This observation also concurs with the findings of Vahedi et al.[25] who found that as the Kinetin concentration kept being increased relative to the 2,4-D levels, Saffron explants by-passed the callus phase to initiate organogenesis. This trend may be explained by the fact that Kinetin is a known suppressor of callus formation.

Two morphologically distinct calli, either embryogenic or nonembryogenic in nature, emerged when cv Brondal leaves were subjected to varying 2,4-D to Kinetin ratios. In the case of cv Brondal, embryogenic calli could only be encouraged when 2,4-D to Kinetin levels were high, $0.5 \mathrm{mg} / \mathrm{L}$ 2,4-D and $0.1 \mathrm{mg} / \mathrm{L}$ Kinetin. Any further increases in 2,4-D to a constant Kinetin was not beneficial as it tended to discourage embryogenic calli formation. In fact, similar to the study's findings of Sabeti et al. [27] working on American Ginseng found that a high auxin to cytokine level inspired somatic embryogenic calli formation. Both studies also showed that, a low auxin to cytokine would depress calli formation altogether and promote direct organogenesis. However, contrary to this study's findings, Das et al.[28] found while working with $B$. racemosa that somatic embryos could be induced when the Kinetin to 2,4-D levels were equal and even when Kinetin levels were twice as high as 2,4-D. This difference in tissue response could be attributed to the fact that tissue response to hormones is usually genotype specific.

During the induction of somatic embryos from cultured $\mathrm{cv}$ Brondal leaves, the calli had to pass through a nonembryogenic phase before achieving embryogenic status. Although this is not a usual occurrence in most plant species [12], it has been known to take place in several Chinese and
Japanese sweet potato cultivars. In fact, Karamian and Ebrahimzadeh [11] found this to be a common feature especially when shoot tips were used to initiate culture. Karamian and Ebrahimzadeh [11] highlighted that shoot tips in culture would first yield nonembryogenic calli before converting into embryogenic calli. This study postulate here that since the $\mathrm{cV}$ Brondal calli was not subcultured but maintained continuously on the original culture plate, the nonembryogenic calli could have acquired the ability to convert to embryogenic calli due to depleting hormonal levels within the original culture media. In support of this, Karamain and Ebrahimzadeh [11] stated that lowered levels of auxins aid in the growth resumption of preembryogenic cells, promoting possible development into embryos.

Plantlets produced via the SE pathway proved to be weak, unviable, and died within four weeks of germination. Although the plantlets had visible apical meristems, the plantlets could not develop beyond the two-leaf stage. This lack of further development might be due to the fact that the embryos were isolated from induction media and placed directly onto plant recovery media without any intervening maturation phase. Mazri et al.[29] has suggested that for successful conversions to plantlets, it was essential for somatic embryos to first go through a maturation period which enables the embryos to reach physiological maturity. Further, in cases where 2,4-D was used to induce SE, the embryo maturation period should be conducted on supportive media containing activated charcoal to absorb any remaining 2,4-D. The auxin 2,4-D has been found to actively inhibit embryo conversion and plantlet recovery [29, 30]. Contrary to the behavior of SE regenerates, plantlets regenerated via direct organogenesis grew vigorously strong, readily rooted, and could be subcultured several times. This difference in behavior between the plantlets regenerated via 
SE and organogenesis could be that in direct organogenesis, the developing plantlets were also obtaining their nutrition from the initial cultured explant leaf, a form of photomixotrophy [31], as the leaf appeared to shrivel up while the plantlet thrived. Yaseen et al.[5] also highlighted that endogenous carbohydrate pools may play important roles in the morphogenesis of several plant species.

\section{Conclusion}

In this study sweet potato $c v$ Brondal plantlets were successfully regenerated using both the organogenesis and somatic embryogenic pathways depending on the 2,4-D to Kinetin hormone ratio used in culture media. Direct organogenesis was achieved by culturing leaf explants onto MS media containing $0.05 \mathrm{mg} / \mathrm{L}$ 2,4-D and $0.5 \mathrm{mg} / \mathrm{L}$ Kinetin while SE was initiated by using $0.5 \mathrm{mg} / \mathrm{L} 2,4-\mathrm{D}$ and $0.1 \mathrm{mg} / \mathrm{L}$ Kinetin in media. Overall, plantlets produced under direct organogenesis became fully independent plants, grew vigorously strong while in contrast plantlets produced under SE were weak and died within four weeks of germinating.

\section{Data Availability}

The data used in the study can be provided upon request to the corresponding author.

\section{Conflicts of Interest}

The authors declare that they have no conflicts of interest.

\section{Acknowledgments}

This work was funded by the Deutscher Akademischer Austausch Dienst (DAAD: A/1395622) in country scholarship to the first author.

\section{References}

[1] E. K. Dery, E. E. Carey, R. T. Ssali et al., "Sensory characteristics and consumer segmentation of fried sweetpotato for expanded markets in Africa," International Journal of Food Science \& Technology, vol. 56, no. 3, pp. 1419-1431, 2021.

[2] T. Denham, H. Barton, C. Castillo et al., "The domestication syndrome in vegetatively propagated field crops," Annals of Botany, vol. 125, no. 4, pp. 581-597, 2020.

[3] H. S. Kim, C.-J. Lee, S.-E. Kim et al., "Current status on global sweetpotato cultivation and its prior tasks of mass production," Journal of Plant Biotechnology, vol. 45, no. 3, pp. 190-195, 2018.

[4] FAOSTAT, FAO Statistics, Food and Agricultural Organization of the United Nations, Rome, Italy, 2011, http://apps. fao.org.

[5] M. Yaseen, T. Ahmad, G. Sablok, A. Standardi, and I. A. Hafiz, "Review: role of carbon sources for in vitro plant growth and development," Molecular Biology Reports, vol. 40, no. 4, pp. 2837-2849, 2013.

[6] S. Mudombi, "Adoption of agricultural innovations: the case of improved sweet potato in Wedza community of Zimbabwe," African Journal of Science, Technology, Innovation and Development, vol. 5, no. 6, pp. 459-467, 2013.
[7] M. K. Razdan, Introduction to Plant Tissue Culture, Science Publishers, Oxford \& IBH Publishing Company Pvt. Limited, New Delhi, India, 2003.

[8] G. K. Rohela, S. Damera, P. Bylla, R. Korra, S. Pendli, and C. Thammidala, "Somatic embryogenesis and indirect regeneration in Mirabilis jalapa Linn," Materials Today: Proceedings, vol. 3, no. 10, pp. 3882-3891, 2016.

[9] Y. Kasukabe, L. He, Y. Watakabe, M. Otani, T. Shimada, and S. Tachibana, "Improvement of environmental stress tolerance of sweet potato by introduction of genes for spermidine synthase," Plant Biotechnology, vol. 23, no. 1, pp. 75-83, 2006.

[10] H. R. Lou, M. S. Maria, J. Benavides, D. P. Zhang, Y. Z. Zhang, and M. Ghislain, "Rapid genetic transformation of sweetpotato (Ipomoea batatas (L.) Lam) via organogenesis," African Journal of Biotechnology, vol. 5, no. 20, 2006.

[11] R. Karamian and H. Ebrahimzadeh, "Plantlet regeneration from protoplast-derived embryogenic calli of Crocus cancellatus," Plant Cell, Tissue and Organ Culture, vol. 65, no. 2, pp. 115-121, 2001.

[12] B. J. Sivparsad and A. Gubba, "Development of an efficient plant regeneration protocol for sweet potato (Ipomoea batatas L.) cv. Blesbok," African Journal of Biotechnology, vol. 11, no. 84, pp. 14982-14987, 2012.

[13] B. M. Kaouther, E. Nadhra, C. Ahlem, A. Jemmali, and P. Druart, "In vitro picloram-induced somatic embryogenesis from leaflets of cherry (Prunus incisa Thunb.)," Journal of Life Sciences, vol. 5, no. 1, pp. 913-920, 2011.

[14] A. Sefasi, J. Kreuze, M. Ghislain et al., "Induction of somatic embryogenesis in recalcitrant sweetpotato (Ipomoea batatas L.) cultivars," African Journal of Biotechnology, vol. 11, no. 94, pp. 16055-16064, 2012.

[15] P. Che, S. Chang, M. K. Simon et al., "Developing a rapid and highly efficient cowpea regeneration, transformation and genome editing system using embryonic axis explants," The Plant Journal, vol. 6, pp. 1-14, 2021.

[16] V. Lakshmanan, S. Reddampalli Venkataramareddy, and B. Neelwarne, "Molecular analysis of genetic stability in longterm micropropagated shoots of banana using RAPD and ISSR markers," Electronic Journal of Biotechnology, vol. 10, no. 1, pp. 106-113, 2007.

[17] H. H. Chung and H. Y. Ouyang, "Use of thidiazuron for highfrequency callus induction and organogenesis of wild strawberry (fragaria vesca),” Plants, vol. 10, no. 1, p. 67, 2021.

[18] V. Verma, G. Zinta, and K. Kanwar, "Optimization of efficient direct organogenesis protocol for Punica granatum L. cv. Kandhari Kabuli from mature leaf explants," In Vitro Cellular \& Developmental Biology - Plant, vol. 57, no. 1, pp. 48-59, 2021.

[19] T. R. Masekesa, E. Gasura, E. Ngadze et al., "Efficacy of Zeatin, Kinetin and Thidiazuron in induction of adventitious root and shoot from petiole explants of sweetpotato cv. Brondal," South African Journal of Botany, vol. 104, pp. 1-5, 2016.

[20] T. Murashige and F. Skoog, "A revised medium for rapid growth and bio assays with tobacco tissue cultures," Physiologia Plantarum, vol. 15, no. 3, pp. 473-497, 1962.

[21] G. Snedecor and W. Cochran, Statistical Methods, Iowa State University, Ames, Iowa, 1969.

[22] S. Von Arnold, I. Sabala, P. Bozhkov, J. Dyachok, and L. Filonova, "Developmental pathways of somatic embryogenesis," Plant Cell, Tissue and Organ Culture, vol. 69, no. 3, pp. 233-249, 2002.

[23] T. Jung, U. Schauer, C. Heusser, C. Neumann, and C. Rieger, "Detection of intracellular cytokines by flow cytometry," 
Journal of Immunological Methods, vol. 159, no. 1-2, pp. 197-207, 1993.

[24] K. Hartig and E. Beck, "Crosstalk between auxin, cytokinins, and sugars in the plant cell cycle," Plant Biology, vol. 8, no. 3, pp. 389-396, 2006.

[25] M. Vahedi, S. Kalantari, and S. Alireza Salami, "Effects of osmolytic agents on somatic embryogenesis of saffron (Crocus sativus L.)," Notulae Scientia Biologicae, vol. 7, no. 1, pp. 57-61, 2015.

[26] U. Rashid, S. Ali, G. M. Ali, N. Ayub, and M. S. Masood, "Establishment of an efficient callus induction and plant regeneration system in Pakistani wheat (Triticum aestivum) cultivars," Electronic Journal of Biotechnology, vol. 12, no. 3, pp. 4-5, 2009.

[27] M. Sabeti, R. Zarghami, and M. E. Zadeh, "Effects of explants and growth regulators on callogenesis and somatic embryogenesis of Agria potato cultivar," International Journal of Agriscience, vol. 3, no. 3, pp. 213-221, 2013.

[28] A. Das, S. Thakur, A. Shukla, P. Singh, J. Ansari, and N. P. Singh, Chickpea: Crop Wild Relatives for Enhancing Genetic Gains, pp. 205-224, Academic Press, Cambridge, Massachusetts, USA, 2020.

[29] M. A. Mazri, R. Naciri, and I. Belkoura, "Maturation and conversion of somatic embryos derived from seeds of olive (olea europaea L.) cv. Dahbia: occurrence of secondary embryogenesis and adventitious bud formation," Plants, vol. 9, no. 11, Article ID 1489, 2020.

[30] A. M. M. D. Nascimento, P. A. Barroso, N. F. F. D. Nascimento et al., "Pinus spp. somatic embryo conversion under high temperature: effect on the morphological and physiological characteristics of plantlets," Forests, vol. 11, no. 11, Article ID $1181,2020$.

[31] M. Escalona, G. Samson, C. Borroto, and Y. Desjardins, "Physiology of effects of temporary immersion bioreactors on micropropagated pineapple plantlets," In Vitro Cellular \& Developmental Biology - Plant, vol. 39, no. 6, pp. 651-656, 2003. 